\title{
PRESENCE OF TASK-1 CHANNEL IN THE LARYNGEAL MUCOSA IN THE NEWBORN LAMB
}

Véronique Bournival $^{\mathrm{a}}$, Claude Roberge ${ }^{\mathrm{b}}$, Shirley Campbell ${ }^{\mathrm{b}}$, Alexandre Doueik ${ }^{\mathrm{c}}$, Louis Gendron ${ }^{\mathrm{b}}$, Marcel Daniel Payet ${ }^{\mathrm{b}}$, Nicole Gallo-Payet ${ }^{\mathrm{b}}$, Jean-Paul Praud ${ }^{\mathrm{a}, \mathrm{b}}$

From the ${ }^{a}$ Neonatal Respiratory Research Unit, Department of Pediatrics; ${ }^{b}$ Department of Physiology/Biophysics; ${ }^{c}$ Department of Pathology, Université de Sherbrooke

Running head: TASK-1 IN LARYNGEAL EPITHELIUM

\section{$\underline{\text { Address for correspondence and reprint requests: }}$}

Jean-Paul Praud MD PhD

Departments of Pediatrics and Physiology

Université de Sherbrooke

J1H 5N4, QC Canada
Phone: (819) 346-1110, ext 14851

Fax: (819) 564-5215

email: Jean-Paul.Praud@USherbrooke.ca 


\section{ABSTRACT (156 words)}

Nearly 40 potassium channels have been described in respiratory epithelial cells. Of these are found several members of the four-transmembrane domain, two-pore $\mathrm{K}^{+}$ channel family (K2P family), namely Twik-1 and -2 , Trek-1 and -2 , Task-2, -3 , and -4 , Thik-1, and KCNK7. The aim of this study was to verify whether the Twik-related Acid Sensitive $\mathrm{K}^{+}$channel, subtype 1 (Task-1) (also known as KCNK3), is present in the laryngeal mucosa in the newborn lamb. Through the use of immunohistochemistry and RT-PCR amplification, results indicate that Task-1 protein and mRNA are present in the laryngeal mucosa, in both the ciliated, pseudostratified columnar (respiratory) epithelium and the non-keratinized, stratified squamous epithelium. The partial sheep-specific mRNA and partial inferred protein sequences showed high homology levels with previously-reported rat, mouse, bovine and human Task-1 sequences. These results represent the first demonstration that Task-1, a pH-sensitive channel responsible for setting membrane potential, is present in the laryngeal mucosa of a newborn mammal.

KEYWORDS: KCNK3; immunohistochemistry; RT-PCR; respiratory epithelium; larynx; lamb 


\section{INTRODUCTION}

Regulation of volume and ionic composition of fluids at the surface of the airways and alveoli is an important function of respiratory epithelium. Numerous channels are expressed in respiratory epithelial cells, including sodium, chloride and potassium channels. While sodium and chloride channels have been the most extensively studied, nearly 40 different potassium channels belonging to the 3 main classes of $\mathrm{K}^{+}$channels have been described in respiratory epithelial cells (1).

In addition to trans-epithelial transport of ion and fluid, respiratory epithelial $\mathrm{K}^{+}$channels appear to be involved in numerous crucial aspects of lung physiology, including gas exchange (oxygen sensing in neuro-epithelial bodies), alveolar stability (surfactant production by alveolar type II cells), epithelial repair after injury (alveolar and bronchial cell migration, proliferation and apoptosis) and inflammatory responses (regulation of immune cell functions) (1). Many of these functions are especially important at birth, when the lungs must adapt from the intra-uterine, liquid milieu to the extra-uterine, aerial environment in a matter of minutes.

Members of the four-transmembrane domain, two-pore $\mathrm{K}^{+}$channel family (K2P family, also known as the KCNK family) are particular among $\mathrm{K}^{+}$channels. Indeed, it is well established that they are responsible for setting membrane potential of epithelial cells, regardless of the voltage and metabolic activity of the cell (2). Several members of the K2P family have been described in respiratory epithelial cells, including Twik-1 and -2 , Trek-1 and -2 , Task-2, -3 , and -4 , Thik-1, and KCNK7 $(3,4)$. Stemming from our extensive program on neonatal laryngeal physiology dating from 20 years, the aim of the 
present study was to investigate for the presence of Task-1 [Twik-related Acid Sensitive $\mathrm{K}^{+}$channel, subtype 1, also called KCNK3 (Potassium Channel, subfamily K, member 3)] in cells from the laryngeal epithelium, more precisely in our newborn ovine model. Indeed, in addition to the important role Task-1 channels are thought to have on the control of trans-epithelial ionic and liquid transport in the respiratory epithelium, the modulation of its activity by extracellular acidity as well as both local and inhaled anesthetics (2) would make the laryngeal epithelium a special location for Task-1 channel activity. Finally, studying the larynx mucosa also enables to test for the presence of Task1 channels not only in the respiratory epithelium, but also in the squamous, nonkeratinized stratified epithelium covering the epiglottis. Using both immunohistochemistry for protein and RT-PCR amplification for mRNA identification, we report the presence of Task-1 channels in the newborn ovine laryngeal epithelium. In addition, we provide partial Task-1 cDNA and protein sequences in the sheep. To our knowledge, this is the first observation of Task- 1 channels in respiratory epithelial cells and the first report of Task-1 cDNA and protein sequences in sheep. 


\section{MATERIALS AND METHODS}

\section{ANimals}

Laryngeal tissues were dissected from 5 lambs aged 5 - 12 days and weighing between 5 and $7 \mathrm{~kg}, 5-10$ minutes after euthanasia by an overdose of pentobarbital sodium (90 $\mathrm{mg} / \mathrm{kg}$ IV). The study protocol was approved by the Committee for Animal Care and Experimentation of the Université de Sherbrooke.

\section{ANTIBODIES AND REAGENTS}

The chemicals used in the present study were obtained from the following sources: antiTask-1 antibody and its control peptide from Alomone (Jerusalem, Israel); unmasking solution, avidin/biotin blocking kit, normal serum, biotinylated secondary antibody, Vectastain ABC kit, DAB Substrate Kit for peroxidase, hematoxylin and VectaMount Permanent Mounting Medium from Vector Laboratories (Burlingame, Canada); RNAqueous $^{\circledR}-4$ PCR from Ambion (Austin, TX); oligo (deoxythymidine) ${ }_{15}$ (oligo(dT) ${ }_{15}$ ) primers, rRNasin Ribonuclease Inhibitor, Moloney murine leukemia virus reverse transcriptase (M-MLV RT), first 5X M-MLV buffer, DNA ladders and pGEM-T Easy Vector from Promega (Madison, WI); deoxynucleotide triphosphates (dNTPs) from Amersham Pharmacia Biotech (Oakville, Canada) and Qiaquick gel extraction kit from Qiagen (Mississauga, Canada).

\section{IMMUNOHISTOCHEMISTRY}

The whole larynx was immersed immediately after removal in $3.7 \%$ paraformaldehyde for at least 24 hours. The tissue was then cut longitudinally (5) and embedded in 
paraffin. Three- $\mu$ m-thick sections were mounted on polarized glass slides and rehydrated through consecutive xylene and graded alcohol series and then processed for conventional immunohistochemistry as follows: slides were first immersed in tap water for 5 minutes and incubated 10 minutes in $0.1 \%$ sodium dodecyl sulfate to increase cell membrane permeability. Thereafter, slides were boiled 3 minutes in unmasking solution. After blockade of endogenous peroxidase activity by a $0.3 \%$ hydrogen peroxide solution for 30 minutes at $4{ }^{\circ} \mathrm{C}$, the sections were rinsed in phosphate buffered saline (PBS), followed by a 30-min incubation in avidin/biotin blocking kit. The slides were then treated for 20 minutes with blocking serum (1.5\% normal serum in PBS) and incubated overnight with the primary anti-Task-1 antibody, diluted (1:100) in the blocking serum. Non-specific interactions were assessed by pre-incubation of the antibody with the corresponding blocking peptide $(2 \mu \mathrm{g}$ peptide: $1 \mu \mathrm{g}$ antibody). Thereafter, slides were thoroughly rinsed in PBS and incubated 45 minutes with biotinylated secondary antibody diluted (1:200) in $0.02 \%$ normal serum in PBS. Finally, after 2 rinses in PBS, slides successively underwent treatment with avidin-biotin-peroxidase complex (Vectastain $\mathrm{ABC}$ kit) for 30 minutes, a peroxidase reaction using 3,3'-diaminobenzidine in the presence of $0.05 \% \mathrm{H}_{2} \mathrm{O}_{2}$ as a chromogen (DAB Substrate Kit) until attainment of a good coloration (on average for 3 minutes), followed by hematoxylin staining. Slides were mounted with a Permanent Mounting Medium (VectaMount) and images acquired with a Leica DFC350 FX camera under a Leica DM4000B microscope (Leica Microsystems Inc., Canada). 


\section{RT-PCR}

Laryngeal mucosa scrapings were collected from one lamb, placed into liquid nitrogen in several aliquots and subsequently stored at - $80 \mathrm{C}$ until RNA extraction. Total RNA was extracted using the RNAqueous ${ }^{\circledR}-4 \mathrm{PCR}$, then treated with deoxyribonuclease I to digest contaminating genomic DNA, according to the manufacturer's recommendations. Total RNA concentration was determined by optic density $(260 \mathrm{~nm})$ while RNA quality was assessed by visualization of $28 \mathrm{~S}$ and $18 \mathrm{~S}$ ribosomal RNA after electrophoresis on denaturing $1 \%$ agarose gel. Reverse transcription (RT) reaction was performed with a GeneAmp PCR System 2400 (Perkin Elmer). Total RNA ( $2 \mu \mathrm{g})$ was first denatured (70 ${ }^{\circ} \mathrm{C}, 10 \mathrm{~min}$ ) in the presence of $0.5 \mu \mathrm{g}$ of oligo $(\mathrm{dT})_{15}$ primers and then reversed transcribed at $42 \mathrm{C}$ for $60 \mathrm{~min}$ in $25 \mu \mathrm{l}$ of $1 \mathrm{X}$ RT buffer [ $50 \mathrm{mM}$ Tris- $\mathrm{HCl}(\mathrm{pH} 8.3), 75$ $\mathrm{mM} \mathrm{KCl}$ and $3 \mathrm{mM} \mathrm{MgCl} 2$ ] containing $10 \mathrm{mM}$ dithiothreitol, $400 \mu \mathrm{M}$ dNTPs, $25 \mathrm{U}$ ribosomal RNasin ribonuclease inhibitor and $400 \mathrm{U}$ M-MLV RT. The latter was then inactivated $\left(70{ }^{\circ} \mathrm{C}, 10 \mathrm{~min}\right)$. Task-1 primers used in this study were specifically designed for sheep by the Cornfield team (6). These primers were based on the human Task-1 sequence, since the sheep Task-1 gene sequence is not known (sense primer: 5'TCA TCG TGT GCA CCT TCA CCT A'3; antisense primer: 5'GGT ACC TCA CCA AGG TGT TGA T'3 (6). In addition, a longer version of these primers were used, with an added base at the 3' end for the sense and antisense primers, in order to obtain a GC clamp for increased PCR efficiency (sense: 5'TCA TCG TGT GCA CCT TCA CCT AC'3; antisense: 5'GGT ACC TCA CCA AGG TGT TGA TG'3). The PCR was carried out using $1 \mu \mathrm{cDNA}, 10 \mathrm{mM}$ Tris- $\mathrm{HCl}(\mathrm{pH} 9.0$ ), $50 \mathrm{mM} \mathrm{KCl}, 1.5 \mathrm{mM} \mathrm{MgCl} 2,400 \mu \mathrm{M}$ dNTPs, $400 \mathrm{nM}$ of each primer, and 1 unit of DNA Taq polymerase deoxynucleotide 
triphosphates $(10 \mathrm{mM})$. Amplification was performed using a GeneAmp PCR System (Perkin Elmer, Waltham, MA, USA) for 35 cycles consisting of $30 \mathrm{sec}$ at $94{ }^{\circ} \mathrm{C}, 30 \mathrm{sec}$ at $51{ }^{\circ} \mathrm{C}$ or $52.6{ }^{\circ} \mathrm{C}$ and $40 \mathrm{sec}$ at $72{ }^{\circ} \mathrm{C}$. For visualization, $5 \mu 1$ PCR product was loaded on a $2 \%$ agarose gel stained with ethidium bromide and observed under UV light with a Multimage Light Cabinet (Alpha Innotech Corp., San Leandro, CA, USA). Yielded amplicon was extracted from the gel, purified, and subcloned into pGEM-T Easy Vector and sequenced (Service de Séquençage, Institut de Pharmacologie, Université de Sherbrooke). The obtained sequence was subjected to BLAST analysis for identification. 


\section{$\underline{\text { RESULTS }}$}

\section{IMMUNOHISTOCHEMISTRY}

Immunolocalization of Task-1 in the lamb larynx was performed using an anti-Task-1 specific antibody directed against the rat peptide sequence (C)EDEKRDAEHRALLTRNGQ (corresponding to residues 252-269 of Task-1). Task-1 immunoreactivity was observed in both the non-keratinized, stratified squamous epithelium and the ciliated, pseudostratified columnar (respiratory) epithelium. In the squamous epithelium (Figure 1), Task-1 was homogenously distributed in all epithelial cells (Fig. 1A', A", A"'). In addition, while Task-1 immunostaining was weak in the subepithelial connective tissue, it was intense in cells from the submucosal mucous glands (Fig. 1 A"'), but absent in the cartilage (Figures 1A'). Specificity of Task-1 labeling was confirmed by the absence of staining when Task-1 antiserum was replaced by the control preabsorbed peptide used at matching dilutions and similar exposure times (Figures 1B, 1B' and 1B"). Specific Task-1 immunoreactivity was also observed in ciliated, pseudostratified columnar (respiratory) epithelium (Figure 2). High magnification photomicrographs of the respiratory epithelium (Figure 2A' and $2 \mathrm{~A}^{\prime \prime}$ ) indicated that the protein was mainly present at the apical side of the cells. In addition, goblet cells were not stained with Task-1 antibody (Figure 2A", arrow). Similarly to observations in the squamous epithelium, staining was intense in the submucosal glands. Finally, Task-1 immunostaining was consistently more intense in the squamous (Fig. 1) comparatively to the respiratory epithelium (Fig. 2) in all 3 tested lambs. 


\section{RT-PCR}

As shown in Figure 3, mRNA expression of Task-1 was observed with both short and long primer sequences and at different hybridization temperatures $\left(52.6^{\circ} \mathrm{C}\right.$ and $\left.51{ }^{\circ} \mathrm{C}\right)$, with the obtained amplicon having the expected length (384 bp). Of note, the long primer pair specifically designed for this study led to better amplification than the shorter primer

pair used previously (6). The absence of contaminating genomic DNA was confirmed by the absence of bands in the RT(-) control, which consisted in an omission of the M-MLV RT during the cDNA synthesis from extracted and purified RNA. The $384 \mathrm{pb}$ amplicon, purified from the more efficient PCR condition (Fig. 3 lane D), was subcloned into pGEM-T Easy Vector for sequencing. The obtained Task-1 sequence (338 nu of the 384 nu amplicon), submitted to GenBank as a partial Task-1 sheep cDNA sequence (EU377476), showed a high homology level with the rat $(94.7 \%)$, mouse $(94.7 \%)$, human $(97.6 \%)$ and bovine (predicted, $99.7 \%$ ) equivalent region of Task-1 sequences (Figure 4A). Likewise, the sheep partial inferred protein sequence (GenBank: ABY84672) revealed a high homology level with the rat $(98.2 \%)$, mouse $(98.2 \%)$, human $(99.1 \%)$ and bovine (predicted, $100 \%$ ) equivalent region of Task-1 protein sequences (Fig. 4B). 


\section{DISCUSSION}

To our knowledge, this is the first study 1) showing evidence that the Task-1 channel is present at the apical domain of respiratory epithelial cells and in squamous epithelial cells of the larynx and 2) to provide partial Task-1 cDNA and protein sequences in the sheep.

\section{PRESENCE OF TASK-1 CHANNEL IN THE RESPIRATORY EPITHELIUM OF THE LARYNX}

The presence of Task-1 channel in the respiratory epithelium suggests that this K2P channel shares important functions with other $\mathrm{K}^{+}$channels previously reported in this epithelium (1). The Task-1 channel corresponds to a plasma membrane hole and is responsible for a leak background current, which has a key role in maintaining cell membrane polarization, regardless of voltage and metabolic conditions. Inhibition of Task-1 channel opening causes membrane depolarization and can initiate a number of events, such as liquid and ion transport into and from the airway lumen.

Our observation that Task-1 is primarily localized at the apical domain of the plasma membrane of laryngeal epithelial cells is in agreement with a previous report of Twik-2 and Trek-1, two other K2P channels, at the apical domain of the plasma membrane of human bronchial Calu-3 epithelial cells (3). While results from the latter study showed the presence of functional K2P currents, which constitutively ensure trans-epithelial $\mathrm{K}^{+}$ secretion and recycling, in support of $\mathrm{K}^{+}$-dependent pumps and transporters of the apical membrane, as well as support anion secretion, this remains to be shown for the Task-1 channel. However, the presence of these latter channels in respiratory epithelial cells in the neonatal period suggests that it may be involved in the transition from intra-uterine life, where lung growth depends on the filling of the future airways by $\mathrm{Cl}^{-}$rich liquid 
secreted by the respiratory epithelium (7), to extra-uterine conditions, where the amount of liquid in the airways and alveoli must be restricted to what is necessary for optimal mucociliary clearance (8). Further studies will be required to assess the function of the Task-1 channel in respiratory epithelial cells in both the neonatal period and later on in life.

\section{PresenCe OF TASK-1 ChanNEL IN EPITHELIAL CELLS OF THE SUBMUCOSAL GLANDS}

Our results clearly show that the Task-1 channel is also present in epithelial cells of the submucosal gland. This is reminiscent of a previous report of several $\mathrm{K}^{+}$channels in Calu-3 cells, which are derived from submucosal glands of the respiratory epithelium (3). Moreover, the present data suggest that transepithelial $\mathrm{K}^{+}$secretion via the Task-1 channel is also involved in secretory processes occurring in the respiratory submucosal glands.

\section{PRESENCE OF TASK-1 IN THE SQUAMOUS STRATIFIED EPITHELIUM OF THE LARYNX}

The laryngeal mucosa is comprised not only of a respiratory (ciliated, pseudostratified columnar) epithelium, but also of a non-keratinized, squamous stratified epithelium (9). Of note, the Task-1 channel was readily observed herein in most cells of the squamous epithelium. To our knowledge, this is the first report of the presence of this channel in a nonkeratinized, stratified squamous epithelium. Again, while our results do not provide specific insight with regard to the physiological function of the Task-1 channel in such an epithelium, previous reports lead us to suggest that Task channels could be involved in the control of inflammation (10) and intense cell death $(11,12)$ and proliferation $(13)$, 
occurring during laryngeal epithelial repair in response to offending agents such as alcohol, cigarette smoke and laryngo-pharyngeal reflux (14). Interestingly, the ciliated respiratory epithelium of the larynx is often replaced by squamous epithelium in smokers (9), which, together with results from animal studies, suggests that the squamous epithelium of the larynx has a protective role against irritating substances (15).

\section{Potential Physiological IMPORTANCE OF TASk-1 FOR THE LARYNGeal}

\section{EPITHELIUM}

Several physicochemical factors are known to stimulate (inhalational anesthetics) or inhibit (extra-cellular acidification, hypoxia, local anesthetics) Task-1 channel activity (2). Furthermore, all of the above modulating factors of Task-1 channel activity appear especially relevant to the larynx. Indeed, extracellular acidification of the laryngeal mucosa is frequent during laryngo-pharyngeal reflux of acid gastric liquid and triggers the laryngeal chemoreflexes, which include swallowing, expiratory reflex and cough in the mature mammal in contrast to apnea, bradycardia and laryngospasm in the premature newborn mammal $(16,17)$. Overall, the available literature suggests that laryngeal chemoreflexes are involved in apneas of prematurity, apparent life-threatening events of infancy and sudden infant death syndrome. However, while the Task-1 channel appears to be involved in acid taste transduction in the mouse (18), its involvement in the laryngeal chemoreflexes triggered by acid reflux is not straightforward. Indeed, the Task1 channel goes from open to shut within the physiological $\mathrm{pH}$ range (respectively from 7.45 to 7.35 ) (19), which is well above the $\mathrm{pH}$ value of gastric refluxates $(<4)$, at least outside of the postprandial period. In addition, the potential physiological consequences 
of Task-1 channel activity modulation by hypoxia $(20,21), \mathrm{CO}_{2}$ breathing $(21,22)$, inhalation of volatile anesthetics (23) or application of local anesthetics (24), which are relatively frequent laryngeal conditions, are currently unknown.

IN CONCLUSION, the present results show for the first time that the Task- 1 channel is present in the laryngeal mucosa, at the apical domain of plasma cell membrane in both the squamous and respiratory epithelium in newborn lambs. The physiological functions of the Task-1 channel in airway cells remain to be elucidated. 


\section{ACKNOWLEDGMENTS}

The authors wish to acknowledge the expert technical assistance of Jean-Philippe Gagné.

This work was supported by an operating grant from the Canadian Institutes of Health

Research, NRF 15558. Louis Gendron, Marcel Daniel Payet, Nicole Gallo-Payet and Jean-Paul Praud are members of the FRSQ-funded Clinical Research Center Étienne-Le Bel, Université de Sherbrooke.

\section{DECLARATION OF INTEREST}

The authors report no conflicts of interest. The authors alone are responsible for the content and writing of the paper. 


\section{REFERENCES}

1. Bardou $\mathrm{O}$, Trinh NT, Brochiero E: Molecular diversity and function of $\mathrm{K}+$ channels in airway and alveolar epithelial cells. Am J Physiol Lung Cell Mol Physiol. 2009; 296: L145-155.

2. Bayliss DA, Barrett PQ: Emerging roles for two-pore-domain potassium channels and their potential therapeutic impact. Trends Pharmacol Sci. 2008; 29: 566-575.

3. Davis KA, Cowley EA: Two-pore-domain potassium channels support anion secretion from human airway Calu-3 epithelial cells. Pflugers Arch. 2006; 451: 631-641.

4. Inglis SK, Brown SG, Constable MJ, McTavish N, Olver RE, Wilson SM: A $\mathrm{Ba} 2+$-resistant, acid-sensitive $\mathrm{K}+$ conductance in $\mathrm{Na}+$-absorbing $\mathrm{H} 441$ human airway epithelial cells. Am J Physiol Lung Cell Mol Physiol. 2007; 292: L1304L1312.

5. Westra WH, Hruban RH, Phelps TH, Isacson C: Surgical pathology dissection, an illustrated guide, 2nd ed. New-York: Springer-Verlag; 2003.

6. Cornfield DN, Resnik ER, Herron JM, Reinhartz O, Fineman JR: Pulmonary vascular $\mathrm{K}+$ channel expression and vasoreactivity in a model of congenital heart disease. Am J Physiol Lung Cell Mol Physiol. 2002; 283: L1210-1229.

7. Hooper SB, Wallace MJ: Role of the physicochemical environment in lung development. Clin Exp Pharmacol Physiol. 2006; 33: 273-279.

8. Chilvers MA, O'Callaghan C: Local mucociliary defence mechanisms. Paediatr Respir Rev. 2000; 1:27-34. 
9. Mills SE: Histology for pathologists, 3rd ed. Philadelphia: Lippincott, Williams \& Wilkins; 2006.

10. Bittner S, Meuth SG, Göbel K, Melzer N, Herrmann AM, Simon OJ, Weishaupt A, Budde T, Bayliss DA, Bendszus $\mathrm{M}$, Wiendl H: TASK1 modulates inflammation and neurodegeneration in autoimmune inflammation of the central nervous system. Brain. 2009; 132: 2501-2516.

11. Lauritzen I, Zanzouri M, Honoré E, Duprat F, Ehrengruber MU, Lazdunski M, Patel AJ: K+-dependent cerebellar granule neuron apoptosis. Role of Task leak K+ channels. J Biol Chem. 2003; 278: 32068-32076.

12. Yun J, Kim S, Bang H: TASK-1 Channel Promotes Hydrogen Peroxide Induced Apoptosis. Korean J Physiol Pharmacol. 2005; 9: 63-68.

13. Patel AJ, Lazdunski M: The 2P-domain K+ channels: Role in apoptosis and tumorigenesis. Pflugers Arch. 2004; 448: 261-273.

14. Gale N, Michaels L, Luzar B, Poljak M, Zidar N, Fischinger J, Cardesa A: Current review on squamous intraepithelial lesions of the larynx. Histopathology. 2009; 54: 639-656.

15. Osimitz G, W Droege W, Finch JM: Toxicologic significance of histologic change in the larynx of the rat following inhalation exposure: A critical review. Toxicol Appl Pharmacol. 2007; 225: 229-237.

16. Thach BT: Some aspects of clinical relevance in the maturation of respiratory control in infants. J Appl Physiol. 2008; 104: 1828-1834. 
17. St-Hilaire M, Samson N, Nsegbe E, Duvareille C, Moreau-Bussiere F, Micheau P, Lebon J, Praud JP: Postnatal maturation of laryngeal chemoreflexes in the preterm lamb. J Appl Physiol. 2007; 102: 1429-1438.

18. Richter TA, Dvoryanchikov GA, Chaudhari N, Roper SD: Acid-sensitive twopore domain potassium (K2P) channels in mouse taste buds. J Neurophysiol. 2004; 92: 1928-1936.

19. Duprat F, Lesage F, Fink M, Reyes R, Heurteaux C, Lazdunski M: TASK, a human background $\mathrm{K}+$ channel to sense external $\mathrm{pH}$ variations near physiological pH. EMBO J. 1997; 16: 5464-5471.

20. Johnson RP, Fearon IM: GABA(B) receptor activation augments TASK-1 in MAH cells and mediates autoreceptor feedback during hypoxia. Biochem Biophys Res Commun. 2003; 312: 421-425.

21. Trapp S, Aller MI, Wisden W, Gourine AV: A role for TASK-1 (KCNK3) channels in the chemosensory control of breathing. J Neurosci. 2008; 28: 88448850.

22. Bradford A, McKeogh D, O'Regan RG: Laryngeal-receptor responses to phasic CO2 in anesthetized cats. J Appl Physiol. 1998; 85: 1135-1141.

23. Putzke C, Hanley PJ, Schlichthörl G, Preisig-Müller R, Rinné S, Anetseder M, Eckenhoff R, Berkowitz C, Vassiliou T, Wulf H, Eberhart L: Differential effects of volatile and intravenous anesthetics on the activity of human TASK-1. Am J Physiol Cell Physiol. 2007; 293: C1319-1326.

24. Nielson DW, Ku PL, Egger M: Topical lidocaine exaggerates laryngomalacia during flexible bronchoscopy. Am J Respir Crit Care Med. 2000; 161: 147-151. 


\section{FIGURE}

Figure 1:
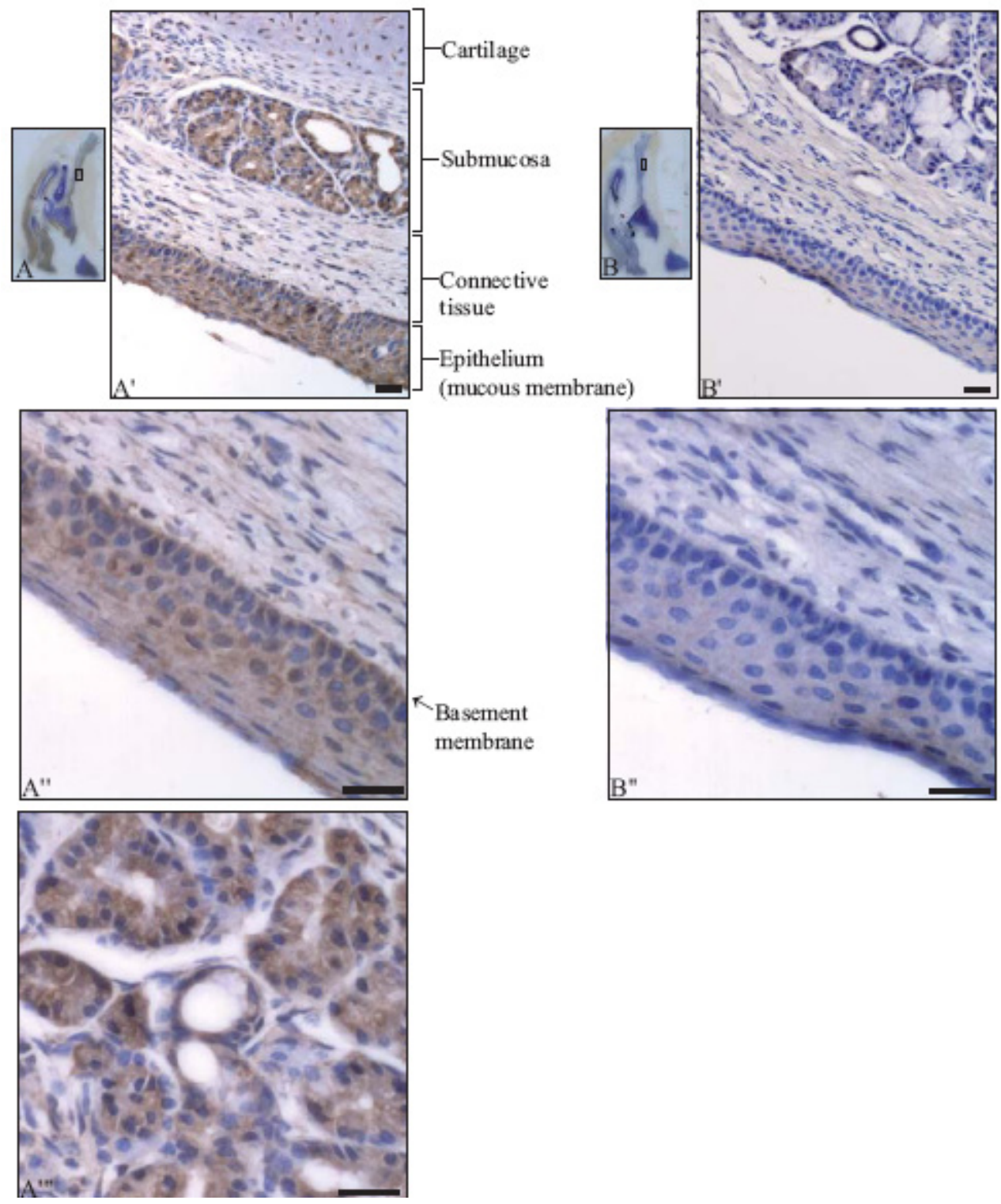
Figure 2:
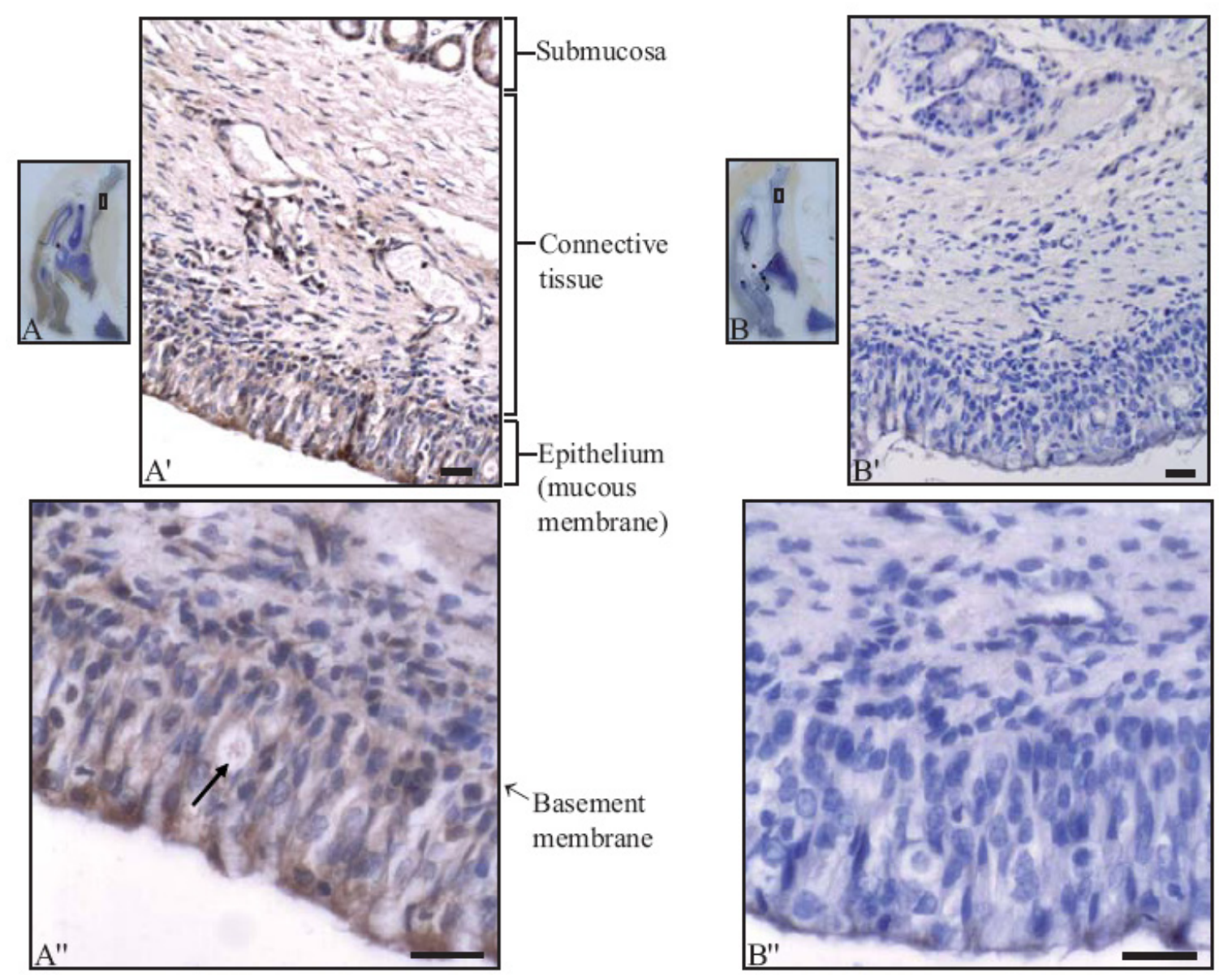
Figure 3:

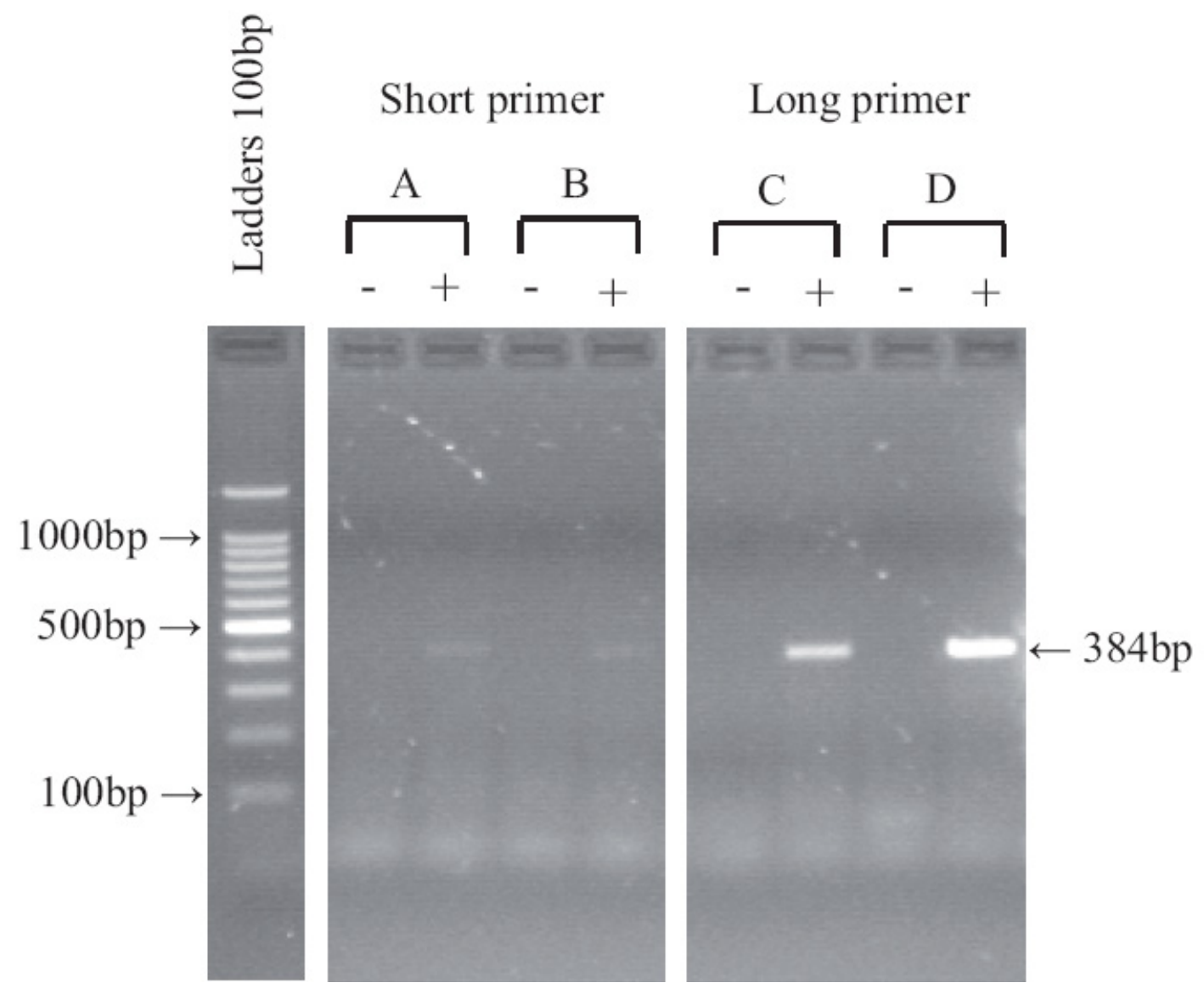


Figure 4:

A

TASK-1 Oa

TASK-1 Bt predicted

TASK-1 HS

Task-1 Mm

Task-1 Rn

TASK-1 Oa

TASK-1 Bt predicted

TASK-1 Hs

Task-1 Mm

Task-1 Rn

TASK-1 Oa

TASK-1 Bt predicted

TASK-1 Hs

Task-1 Mm

Task-1 Rn

TASK-1 Oa

TASK-1 Bt predicted

TASK-1 HS

Task-1 Mm

Task-1 Rn

TASK-1 Oa

TASK-1 Bt predicted

TASK-1 Hs

Task-1 Mm

Task-1 Rn

TASK-1 Oa

TASK-1 Bt predicted

TASK-1 HS

Task-1 Mm

Task-1 Rn

\section{B}

TASK-1 Oa

Task-1 Bt predicted

TASK-1 Hs

Task-1 Mm

Task-1 Rn

TASK-1 Oa

Task-1 Bt predicted

TASK-1 Hs

Task-1 Mm

Task-1 Rn
CTGCTGGT GGGCGCCGCGGTCTTCGACGCGCTCGAGTCGGAGCCGGAGATGATCGAGCGG CTGCTGGT GGGCGCCGCGGTCTTCGACGCGCTCGAGTCGGAGCCTGAGATGATCGAGCGG CTGCTGGT GGGCGCCGCGGTCTTCGACGCGCTGGAGTCGGAGCCCGAGCTGATCGAGCGG CTGCTGGT GGGCGCCGCGGTGTTCGACGCACTGGAGTCGGAGCCGGAGATGATCGAGCGG CTGCTGGTGGGCGCCGCGGTGTTCGACGCGCTGGAGTCGGAGCCGGAGATGATCGAGCGG

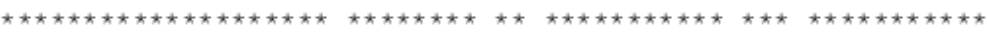

CAGCGGCTGGAGCTGCGGCAGCAGGAGCTGCGAGCGCGCTACAACCTCAGCCAGGGCGGC CAGCGGCTGGAGCTGCGGCAGCAGGAGCTGCGAGCGCGCTACAACCTCAGCCAGGGCGGC CAGCGGCT GGAGCTGCGGCAGCAGGAGCTGCGGGCGCGCTACAACCTCAGCCAGGGCGGC CAGCGGCT GGA GC TGCGGCAGCT GGA GC TGCGGGCGCGCTACAACC TCAGCGAGGGCGGC CAGCGGCT GGAGCTGCGGCAGCTGGAGCTGCGGGCGCGCTACAACCTCAGCGAGGGCGGC

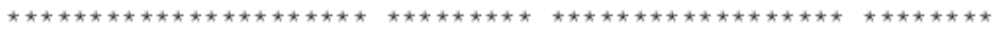

TACGAGGA GCTCGAGCGCGTCGTGCT GCGCCTCAAGCCGCA CAAGGCCGGCGTGCAGTGG TACGAGGAGCTCGAGCGCGTCGTGCTGCGCCTCAAGCCGCACAAGGCCGGCGTGCAGTGG TACGAGGA GCT GGAGCGCGTCGT GCT GCGCCTCAAGCCGCACAAGGCCGGCGT GCA GT GG TACGAGGAGCTGGAGCGCGTCGTGCTGCGCCTCAAGCCGCACAAGGCCGGCGTGCAGTGG TACGAGGAGCTGGAGCGCGTCGTGCT GCGCCTCAAGCCGCACAAGGCCGGCGT GCA GT GG

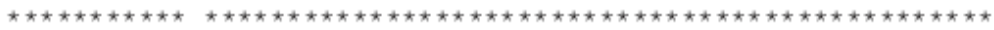

CGCTTCGCCGGCTCCT TCTACTTCGCCA TCACCGTCATCACCACCATCGGCTACGGCCAC CGCTTCGCCGGCTCCT TCTACTTCGCCA TCACCGTCATCACCACCA TCGGC TACGGCCAC CGCTTCGCCGGCTCCT TC TACTTCGCCATCACCGTCAT CACCACCATCGGCTACGGGCAC CGCTTCGCCGGCTCCT TCTACTTCGCCATCACCGTCATCACCACCA TCGGCTATGGTCAT CGCTTCGCCGGCTCCT TCTACTTCGCCATCACCGTCATCACCACAATCGGCTATGGTCAT

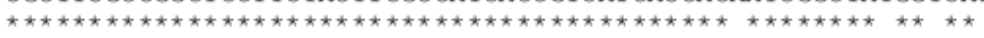

GCGGCACCCAGCACCGATGGCGGCAAGGTGTTCTGCATGTTCTACGCGCTGCTGGGCATC GCGGCACCCAGCACCGATGGCGGCAAGGTGTTCTGCATGTTCTACGCGCTGCTGGGCATC GCGGCACCCAGCACGGAT GGCGGCAAGGTGT TCTGCAT GTTCTACGCGCTGCTGGGCATC GCGGCGCCCAGCACGGACGGAGGCAAGGTGTTCTGCATGTTCTACGCGCTGCTGGGCATC GCGGCTCCCAGCACGGACGGAGGCAAGGTGTTCTGCATGTTCTACGCGCTGCTGGGCATC

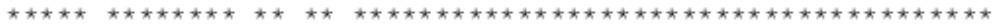

CCGCTCACGCTGGTCATGTTCCAGAGCCTGGGCGAGCG CCGCTCACGCTGGTCATGTTCCAGAGCCTGGGCGAGCG CCGCTCACGCTCGTCATGTTCCAGAGCCTGGGCGAGCG CCGCTCACACTAGTCATGTTCCAGAGCCTGGGTGAACG CCGCTCACACTAGTCATGTTCCAGAGCCTGGGTGAACG

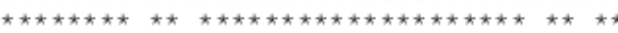

LLVGAAVEDALESE PEMIERQRLE LRQQELRARY NL SQGGYEELERVVLRLKPHKAGVQW LLVGAAV FDALE SE PEM IERQRLE LRQQE LRARYNL SQGGY EELERVVLRLKPHKAGVQW LLVGAAVFDALE SE PEL IERQRLE LRQQE LRARY NL SQGGYEELERVVLRLKPHKAGVQW LLVGAAVFDALE SE PEM IERQRLE LRQLE LRARYNL SEGGYEELERVVLRLKPHKAGVQW LLVGAAVFDALESE PEMIERQRLE LRQLELRARYNL SEGGYEELERVVLRL KPHKAGVQW

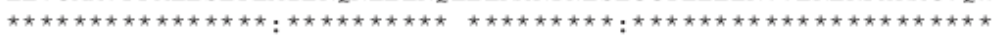

RFAGSFYFA ITVITTIGYGHAAPSTDGGKVFCMFYALLG IPLTLVMFQSLGER RFAGSFYFA ITVITTIGYGHAAPSTDGGKVFCMFYALLG IPLTLVMFQSLGER RFAGSFYFA ITVITTIGYGHAAPS TDGGKVFCMFYALLG IPLTLVMFQSLGER RFAGSFYFA ITVITTIGYGHAA PS TDGGKVFCMFYA LLG IPLTLVMFQS LGER RFAGSFYFA ITVITTIGYGHAAPSTDGGKVFCMFYALLG IPLTLVMFQSLGER

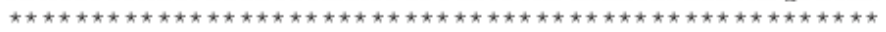

“*” Indicates positions which have a single, fully conserved residue

":" Indicates that one of the following « strong " groups is fully conserved 


\section{FIGURE LEGENDS}

Figure 1. Immunohistochemical localization of the Task-1 channel in the non-keratinized stratified squamous epithelium of the lamb larynx.

Inset $\mathrm{A}$ is a general scan of a lamb larynx slide. Insets A' (magnification $200 \mathrm{X}$ ) and A", (magnification $500 \mathrm{X}$ ) illustrate intense Task-1 labeling in all epithelial cells, weak labeling in the subepithelial connective tissue and absence of labeling in the cartilage. Inset A" illustrates intense Task-1 labeling in submucosal gland cells (magnification $500 \mathrm{X})$. Insets B, B', and B" are the corresponding negative controls obtained using the control preabsorbed peptide. Scale bars $=20 \mu \mathrm{M}$.

Figure 2. Immunohistochemical localization of the Task-1 channel in the ciliated pseudostratified columnar epithelium of the lamb larynx.

Inset A is a general scan of a lamb larynx slide. Insets A' (magnification 200X) and A" (magnification 500X) illustrate Task-1 labeling in epithelial cells, weak labeling in the subepithelial connective tissue and absence of labeling in goblet cells (see arrow in inset A"). Insets B, B', and B" are the corresponding negative controls obtained using the control preabsorbed peptide. Scale bars $=20 \mu \mathrm{M}$.

Figure 3. Expression of Task-1 mRNA in lamb laryngeal mucous membrane.

RT-PCR products of total RNA extraction, which were reverse-transcribed using $(+)$ or not (-) M-MLV RT and amplified using a DNA Taq polymerase, are presented. Lanes A and B represent results obtained using the "short" Task-1 primer pair with hybridization temperatures of $52.6{ }^{\circ} \mathrm{C}$ and $51{ }^{\circ} \mathrm{C}$ respectively. Lanes $\mathrm{C}$ and $\mathrm{D}$ represent results obtained 
using the "long" Task-1 primer pairs and with hybridization temperatures of $52.6{ }^{\circ} \mathrm{C}$ and $51{ }^{\circ} \mathrm{C}$ respectively.

Figure 4. ClustalW alignment of sheep Task-1 partial mRNA sequence and corresponding protein sequence.

A : Alignment of sheep (Oa, Ovis aries: EU377476) Task-1 partial sequence (338 pb) with the equivalent region from human (Hs, Homo sapiens: NM_002246.1 : nu 180-517), mouse (Mm, Mus musculus: NM_010608.2 : nu 202-539), rat (Rn, Rattus norvegicus: NM_033376.1: nu 158-495) and predicted bovine (Bt (predicted), Bos taurus: XM_597401.3: nu 55-392) TASK-1 sequences. B : Alignment of sheep TASK-1 protein sequence (ABY84672), corresponding to the partial mRNA sequence shown in A, with the equivalent protein sequences corresponding to human (NP_002237), mouse (NP_034738), rat (NP_203694) and predicted bovine (XP_597401) TASK-1 mRNA sequences shown in $\mathrm{A}$. 